\title{
Comentario a un caso de fístula uretro- vaginal concomitante con embarazo
}

\author{
Doctor Alvaro Fonnegra Miramón
}

Jefe de Clínica Ginecológica del Hospital de San Juan de Dios.

Historia clínica de febrero $15 / 54$.

Antecedentes.-Nombre: N. N., edad, treinta y cuatro años. Casada hace cinco años.

Menarquia a los 15 años. Ciclo, 5 X 26. Algomenorrea al principio de la menarquia. Actualmente presenta un embarazo de seis meses y medio (está siendo controlada en el servicio de prenatal de los Seguros Sociales). Enferma con antecedentes de 2 abortos a repetición en el curso de un año y medio, de dos y medio a cinco meses, respectivamente. Serología negativa. Manifiesta que, gracias al cuidado prestado en el servicio prenatal, ha logrado llegar en este embarazo a los 6 mises y medio.

La enferma se presenta al servicio quirúrgico de San José en estado de shock con hemorragia vaginal en bastante cantidad, con coágulos y salida de orina por la vagina.

Examen: enferma pálida, con 100 pulsaciones por minuto; ansiosa. Tensión arterial: 10 de máxima por 6 de mínima.

Examen ginecológico: signos clínicos de un embarazo normal de 6 meses y medio, con ruidos fetales positivos.

Genitales externos: se aprecia la salida por la vulva de hemorragia con coágulos, mezclada con un líquido, al parecer orina; al espéculum cuidadosamente aplicado se ve un trayecto fistuloso en la porción media de la uretra, anfractuoso, de 2 centímetros, por 3. c c., de donde fluye sangre y orina mezclacias, en apreciabie cantidad. Resto de vagina, normal. Cuello, al parecer, normal. Al paso de una pequeña sonda vesical se comprueba la existencia de la comunicación uretro-vaginal con las caracteristicas ya anotadas. 
En el interrogatorio la enferma manifiesta que a raíz de un esfuerzo, sintió súbitamente, y sin dolor, la salida por la vagina de sangre mezclada con un líquido claro. Llegó hasta la Clínica Primero de Mayo, y después de un examen, los médicos resolvieron mandarla en una ambulancia al hospital.

En vista del estado de la enferma, se le ordena una transfusión de 500 c. c. de sangre total, solución dextrosada, al $5 \%$ y sedantes. Se le pasa una sonda de nelatón delgada, y se espera un tiempo prudencial para resolver la conducta.

Pasado un período de tiempo aproximadamente de una hora, $\mathrm{y}$ en vista de que la hemorragia no cesa, se resuelve intentar el cierre de la fístula. Previa sedación uterina, se administra una anestesia adecuada y se procede a la intervención. Se practica el método de desdoblamiento de las dos mucosas, vesical y vaginal, y se hace un cierre en dos planos, previo desbridamiento y arreglo de las anfractuosidades de la herida. Hay que hacer notar que el acto quirúrgico se realizó en condiciones difíciles, pues dadas las condiciones de embarazo, no se podía traccionar el cuelio uterino ni efectuar ninguna maniobra brusca en la vagina. Se deja sonda de Foley a permanencia.

Evolución.-La enferma sale en mejores condiciores de la sala. Se le ordenan sedantes uterinos, además de su pcst-operatorio corriente.

A las 3 a. m. me llaman con arózencia del hospital, diciéndome que la enferma, en un corto tiempo, tuvo un parto prematuro. Llego rápidamente y encuentro que por un error de la enfermera, al tratar de traccionar prematuramente la placenta antes del alumbramiento, el interno me informa, que hay la yosibilidad de que se hubiera retenido un pequeño cotiledón. Se ánota que el niño vivió media hora:

Ante el hecho posible de una retención, exploro digitalmente el útero, y aunque no encuentro resto placentario pongo en vigilancia estricta a la enferma. El globo uterino es normal y no hay hemorragia. Las suturas están en su sitio y el funcionamiento de la sonda se hace normalmente.

A los cuatro días comienzan alzas de temperatura hasta de 40 grados. Del lado izquierdo, en región de fosa iliaca, crecimiento de una tumefacción que llega casi hasta el ombligo. Mal estado general, 120 pulsaciones y temperatura de 40 grados. Al tacto se aprecia tumefacción anexial izquierda (¿anexitis post-parto?) Se palpa matriz desviada hacia la derecha en sub-involueión. 
Se resuelve insistir en el tratamiento médico. Se prescribe terramicina endovenosa, $250 \mathrm{mg}$. cada 12 horas. Continuar reposo absoluto; hielo en el abdomen; vigilancia de la emisión de orina y funcionamiento de la sonda. Durante diez días más se vigila estrictamente. Al cabo de éstos, la tumefacción anexial comienza a disminuir el estado general mejora y la fiebre decrece. Al nuevo control ginecológico se nota la desaparición casi completa de ia tumefacción anexial, matriz de tamaño normal, estado general de la enferma, bueno.

La enferma se moja un poco todavía con orina, pues la sutura uretral resume.

Se deja tres días más la sonda y se retira al cabo de los cuales la enferma manifiesta que no se ha vuelto a mojar. Se espera tres días más, antes de darle la salida del hospitai, y se efectúa un chequeo ginecológico. Las suturas han prendido normalmente y no hay rezumamiento de la orina hacia la vagina.

La enferma se controla pasados dos meses, y está, en buenas condiciones.

\section{Discusión de la etiología y la conducta}

Etiologia de tipo traumático: traumatismo por intento de maniobra abortiva 0 paso de sonda vesical.

No se considera problable, pues la enferma niega rotundamente estos hechos. Además, es una enferma que había sido controlada en el servicio de prenatal, quería tener su hijo, como se ve por el antecedente de dos abortos a repetición, a pesar de tratamiento.

Coito: la enferma manifiesta que hacia dos meses no tenía relaciones con su marido.

Faso de un cálculo por la uretra: siempre presenta dolor súbito, acompañado de la demás sintomatologia. La enferma no tenía antecedentes de esta naturaleza; sin embargo, podría ser la causa.

Ruptura espontánea de la uretra a causa de un esfuerzo físico cualquiera: consideramos que ésta no es causa para producir una ruptura de esas características, pues no hay razón científica para efectuarse. La literatura médica no reporta el primer caso que yo sepa.

Un infarto de uno de los vasos correspondientes a esa región que produjera una necrosis de los tejidos. Se acompaña también 
de dolor súbito; además, el buen éxito del tratamiento de la fístula está en contra de esto. Si hubiera habido ư mal terreno vascular, lo más probable era la necrosis y la formoción de una fístula crónica.

Divertículo de la uretra con formación de un pequeño absceso crónico, el cual se cerró y drenó bruscamente há cia la vagina. Hipótesis que parece la más probable. Refuerzan esta teoría el reblandecimiento y la congestión de los tejidos por el embarazo. Este es un caso, aunque no excepcional, raro. En la literarura extensa que he leído al respecto, mencionan la diverticulosis como una entidad, pero sin proudcir fístulas, y menos en una embarazada en la forma como aquí se relata; por lo tanto, no hay estadística de casos. Sólo en una revista se menciona un caso parecido, en una puérpera.

El doctor Gustavo Escallón me informa que él conoce de tres casos: uno aquí en Colombia, en una mujer, pero no embarazada, y dos en Estados Unidos, de diverticulosis sin fístula.

Discusión del tratamiento: considero que en una enferma con hemorragia persistente por ruptura de la uretra, la conducta más aconsejable es la quirúrgica, previa la sedación uterina del caso.

De los casos en que he logrado informarme dentro de los colegas y los consultados en libros y revistas, el pronóstico de la operación en la gran mayoría de los casos, es malo. Los tejidos se esfacelan y más en una embarazada, y si bien se calma la hemorragia por primera intención, al cabo de los dias las suturas se aflojan y se produce una necrosis de los tejidos, instalándose una fístula permanente de tipo crónico.

Los Profesores Acosta y Ferro me cuentan de un caso parecido en que se gangrenó la uretra. 